\title{
Contrast Enhanced Ultrasonography and Carotid Plaque Imaging: from the Hemodynamic Evaluation to the Detection of Neoangiogenesis - The New Approach to the Identification of the Unstable Plaque: from Morphology to Patophysiology
}

\author{
Maria Fabrizia Giannoni ${ }^{1}$, Edoardo Vicenzini², \\ Claudia Monaco ${ }^{3}$ and Piergiorgio $\mathrm{CaO}^{4}$ \\ ${ }^{1}$ Vascular Ultrasound Investigation Unit, Vascular Surgery, \\ Department "P. Stefanini", Sapienza University of Rome, \\ ${ }^{2}$ Department of Neurology and Psychiatry, Sapienza University of Rome, \\ ${ }^{3}$ Kennedy Institute of Rheumatology, Imperial College, London, \\ ${ }^{4}$ Vascular Surgery, Department of Cardioscience, S. Camillo-Forlanini Hospital, Rome, \\ 1,2,4Italy \\ ${ }^{3} U K$
}

\section{Introduction}

Ischemic Stroke (IS) represents the third leading cause of death in the Western World and it is particularly relevant because disability is a major frightening issue both for patients' quality of life, as well as for social and therapeutical implications (Engel, 1998).

One of the most frequent causes of Ischemic Strokes and Transient Ischemic Attacks (TIAs) is cerebral embolism that originates from atherosclerotic plaques in the carotid vessels. This "Large artery" (LA) pathogenesis accounts for $25-30 \%$ of all IS, i.e. more than $1 / 4$ million per year, worldwide (Diener, 2004). In patients with a previous manifested TIA or IS, LA atherosclerosis is indeed observed in nearly $70 \%$ of the cases. Nonetheless, IS is proceeded by a TIA only in half of the patients with carotid atherosclerosis while, in the other half, Stroke may occur without the former manifestation of symptoms (Barnett, 1998).

In regards to preventive surgical strategies for carotid artery diseases, two major fundamental trials represent a "cornerstone" in treatment strategy of the carotid Strokes: these trials clearly and definitively confirmed the relationship between the risk of neurological events and the degree of the internal carotid artery stenosis. According to data collected from European Carotid Surgery Trial (Rothwell, 2004; ECST, 1991; ECST, 1998) and to the North American Symptomatic Carotid Endarterectomy Trial (Barnett, 1998) Stroke risk is correlated to the presence of hemodynamic internal carotid artery stenosis and occurrence of recent cerebrovascular symptoms. A general consensus has been reached on indications for Carotid Endoarterectomy (CEA), that at present has to be performed in 
experienced centers in patients with: a) symptomatic severe stenosis $(=/>70 \%)$; b) symptomatic stenosis (with soft unstable plaque) $>50 \%$; c) asymptomatic patients with 70-99\% stenosis below 75 years of age (Rothwell, 2004, Goldstein 2010, Hobson 2008, Liapis 2009). On the other hand, the real benefit of CEA in asymptomatic patients, even though affected by severe hemodynamic degree of stenosis is still nowadays controversial and not clearly defined, as demonstrated by ACAS (ACAS, 1995) and ACST (Halliday, 2004) trials: only carotid stenosis $>70 \%$ would benefit from CEA, but only after five years follow-up and only in center where CEA is performed with very low perioperative complication rates (Halliday 2010, Kakkos 2009, Setacci 2009). When stenoses are below this threshold, patients are adressed towards medical therapy, which offers at present good results (Rothwell, 2004; CAPRIE, 1996, Goldberg 2010). Therefore the problem of primary prevention strategy exists for a high number of asymptomatic patients, that may transform into 250.000 new IS per year: in these patients, the surgical approach decided only on the severe degree of internal carotid stenosis may be no more valid.

It is mandatory to ameliorate the balance between risksa nd benefit of CEA in asymptomatic patients: during the last 30 years several potential risk factors have been evaluated to appropriately select subgroups of asymptomatic patients that may really benefit from CEA, but, however, without reaching satisfactory results and clear indications (Abbott, 2007; Nicolaides, 1995). At present, the recent ACES Study performed in asymptomatic patient with severe degree internal carotid artery stenosis $(>70 \%)$ in order to detect risk factors significantly related with the onset of neurological events concluded that only the microembolism identified at 2 hours Transcranial Doppler monitoring is a true and independent predictor of cerebrovascular events., significantly linked with cerebral ischemia (Markus, 2010). For all the these reasons further studies are mandatory in order to select subgroup populations that really benefit of surgical treatment.

New evaluation methods have to be considered: the detection of the unstable, vulnerable plaques will have to use functional investigations methods, and no longer the morphological investigation alone is sufficient. Advances in carotid plaque imaging could allow functional investigations methods and the detection of vulnerable plaques has to be performed according to these new viewpoints. Due to all the above-mentioned controversial points, the risk-benefit and cost-effectiveness of CEA in asymptomatic patients have to be better characterized, identifying the real subpopulations that would really take advantages from a surgical preventive strategy, in favor of a safe secure benefit and long-term outcome. In addition, being Stroke an unforeseeable event that occurs in a wide percentage of cases because of carotid embolic lesions, plaque morphology characterization has represented a fundamental step for the selection of patients at risk of cerebrovascular ischemic events. Nonetheless, in recent years, even all information about degree of stenosis and plaque morphology is not yet considered enough to recognize lesions at risk. New further concepts regarding functional activities of carotid plaques represent the future target to be investigated, in order to indentify the so called "vulnerable plaques" and, consequently, to avoid the disabling ischemic event.

\subsection{The symptomatic plaque from the histological point of view}

Histopathological data collected from carotid specimen of symptomatic patients have clearly identified the different morphological characteristics of the symptomatic plaques (Mauriello, 2010; Fisher, 2005) linked with cerebral ischemia and with the underlying mechanisms of plaque instability. 
Beyond the degree of stenosis, the presence of plaques heterogeneity, large areas of intraplaque hemorrhage or a necrotic lipidic core, the presence of surface ulcerations, represent all peculiar characteristics of symptomatic, complicated carotid plaques. All histological studies have then confirmed that the underlying plaque morphology is an important further predictor of stroke risk (Gronholdt, 2001; Stary, 1995). Several studies have shown that plaque morphology have also to be considered an additional independent predictor of cerebral infarction and that carotid plaques at risk for rupture are not always correlated with the severity of stenosis at bifurcation sites. Other morphological characteristics seem to play a more relevant role (Griffin, 2010).

Several histopathological studies have compared the morphological aspects of carotid plaques removed from symptomatic and asymptomatic patients in attempt to better understand the mechanisms underlying plaque destabilization demonstrated that plaque rupture, thin fibrous cap and thrombogenic plaques with relevant inflammatory infiltration and increase of macrophage cells are main features of symptomatic plaques, prone to be responsible of embolic cerebrovascular events (Spagnoli, 2004; Carr, 1996; Fisher, 2005)

\subsection{Ultrasonography for plaque characterization}

Characterization of plaque morphological aspects seemed an excellent method for risk stratification of neurological events. Over the past twenty years, high-resolution ultrasonography represented a reliable tool for plaque characteristics investigation in vivo and in real-time. Still nowadays Color Duplex Ultrasonography is a reliable, repeatable and noninvasive top-level and first choice investigation method in the evaluation of supraortic vessels.

Historically, in 1983 Reilly and coll. (Reilly, 1983) introduced the first characterization of plaque structure according to data obtained from ultrasound investigations: the concepts of "homogeneous" and "heterogeneous" were introduced in clinical practice to define plaques characteristics related to cerebrovascular risk. Irregular surface and ulcerations has also been identified as morphological features predictors of cerebrovascular events (Dixon, 1982).

In 1985 Johnson and Colleagues (Johnson, 1985) established three different criteria describing plaque composition, including calcified, dense (less hyperechogenic than calcified lesions) or soft plaques (isoechogenic in comparison with blood).

In 1988, Gray-Weale and coworkers (Gray-Weale, 1988) described four different plaque types and proposed a classification of morphological features according to ultrasound imaging: Type 1 (anechoic to echogenic fibrous cap; Type 2 (predominantly, but anechoic areas with echogenic, less than $25 \%$ of the plaque); Type 3 (mostly hyperechoic areas with anechoic, less than $25 \%$ of the plaque); Type 4 (echogenic and homogeneous plaque).

In 1990, Widder (Widder, 1990) proposed a reverse classification, the most anechogenic plaques being assigned to Type IV and the most echogenic to Type I.

In 1993, Geroulakos (Gerulakos, 1993) introduced a modified version of Gray-Weale's classification including a 5th category of unclassified plaque reflecting calcified plaques which may have zones of acoustic shadowing which obscure the deeper part of the arterial wall as well as the vessel lumen.

Only in the following years the relative risk of plaque related to morphological characteristics according to a numerical quantification was the subject of a consensus meeting (De Bray, 1996) on the characterization of plaques: it was finally decided that the echogenicity of the plaque should have be standardized against 3 reference structures: blood flowing to anechoic, sternocleidomastoid muscle for isoechogenic, next to the transverse 
processes of cervical vertebrae for hyperechogenicity Further studies suggested the use of the bright far wall of media-adventitia interface as a reference for hyperechogenicity (Joakimsen, 1997). After these early works many further studies have reported data regarding the successful correlation between the plaque morphology on ultrasound investigation and the histological plaque composition.

To further reduce the possibility of biases due to the subjective evaluation, computerized methods also have been introduced to evaluate echogenicity of carotid plaques. The standardized quantitative computerized assessment of plaque echogenicity by Gray Scale Median (GSM) represents nowadays an objective tool for the definition of the unstable plaques (El-Barghouty, 1995; Biasi, 1999). Data collected from literature have indeed clearly demonstrated that low GSM plaque values identify those lesions that are closely related to the prediction of the risk for embolic events (Biasi, 1999; Mathiesen, 2001).

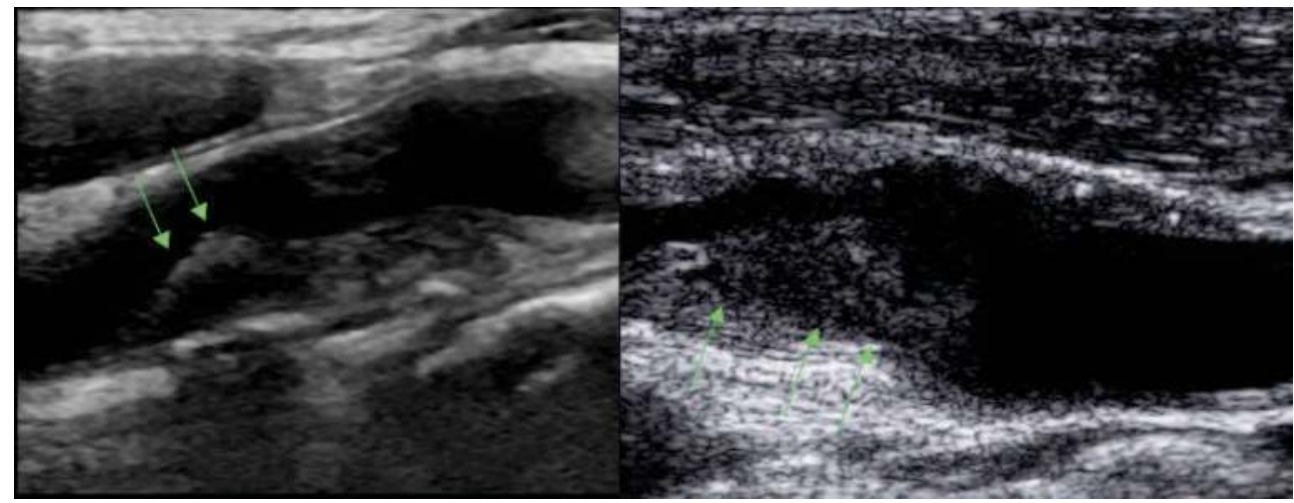

Fig. B-Mode imaging of soft plaques with a clear anechoic part in the distal posterior part of the plaque (green arrows, left) and with a superimposed iso-hypoechoic trhombus (green arrows, right).

\subsection{From morphology to patophysiology}

There is a general agreement that the identification of carotid artery vulnerable lesions is not possible nowadays only relying on the degree of stenosis and plaque morphological characteristics alone. Even if these features represent the conventional methods used for planning adequate treatment strategies, these methods are not capable of evaluating in vivo inflammation and remodeling of unstable plaques, and consequently to predict the true risk of cerebrovascular events. Surface rupture and luminal thrombus formation related to plaque acute inflammation are nowadays considered the major events related to the development of acute stroke.

Techniques aimed at imaging the biological "functional" status of the plaque are now emerging. Conventional radiological imaging such as Computerized Tomography Angiography with contrast agents (CT), Magnetic Resonance Imaging (MRI) and even Positron Emission Tomography (PET) have been recently applied to image targets of the biological functional pathways of carotid plaques. Nonetheless, up-to-date there is no "in vivo" imaging technique considered as the "gold standard" for the demonstration of the direct temporal correlation between inflammation and morphological features of carotid vulnerable plaques responsible of neurological events (Warburton, 2006). Moreover, being 
not widely available and being expensive and radiation risk techniques, these tools cannot be used in the current ordinary follow-up. Despite the excellent results obtained on the validation and accuracy of ultrasonography, the true mechanism able to convert an asymptomatic plaque to a symptomatic one failed to be clearly identified and even if Duplex evaluation represented a further step in the knowledge, it seemed inadequate. Preoperative ultrasound carotid imaging can be used to detect the histological characteristics of plaque with the possibility of post-operative validation. Since recent clinicopathological studies have indicated the role of intraplaque hemorrhage and ulceration in symptomatic carotid disease, identification of these features is of high value in choosing therapy, especially for the asymptomatic patient.

From clinical studies a new concept has emerged: plaque 'vulnerability' i.e. the inner stability and risk for rupture other than morphology and degree of stenosis may be more adequate (Reilly, 1983; Hennerici 2004). Thus, a functional diagnostic test (instead of a pure anatomical imaging) would be preferable as current clinical anatomical investigations have a poor ability to predict which plaques become symptomatic in the immediate future.

\section{Plaque angiogenesis}

The clinical complications of atherosclerosis are caused by local thrombus formation, which results from the rupture and fissuration of surface of an unstable atherosclerotic plaque. The formation of microvessels (angiogenesis) in an atherosclerotic plaque contributes to the development of plaques, increasing the risk of plaque rupture.

Only recently has the in vivo evaluation of angiogenesis received attention for its possible role in assessing the vulnerability of the atheroma. The presence of microvessels in atherosclerotic plaques was firstly described by Paterson in 1936-38 and Geiringer (1951) as well as their lack in the non atherosclerotic - normal, non pathological - arterial wall: these were simply pure observational studies, very far to connect with a patophysiological mechanism. From histological reports it is well known that angiogenesis is linked with the vulnerable, unstable plaque characteristics. Moreover, although the detailed pathophysiological mechanisms of plaque formation and rupture are still under debate, there seems to be reasonable evidence that smooth muscle cell hypertrophy, proliferation and migration through the basal membrane, macrophage infiltration, LDL deposition and intimal neoangiogenesis are crucial steps finally leading to plaque vulnerability and rupture. Histological studies have indeed shown that microvessels are not usually present in the normal human intimal layers and that intima becomes vascularized only with the development of the atherosclerotic process and when its layer grows in thickness (Geiringer, 1951).

Only in the last 20 years the presence of the adventitial vasa vasorum and the occurrence of plaque neovascularization was recognized and identified as a significant marker of plaque instability and confirmed in histological studies, as predictors of unstable atheromasic lesions in cerebro and cardiovascular patients (McCarthy, 1999; Mofidi, 2001).

\section{Ultrasound contrast agents for functional plaque imaging}

In the last few years, Contrast Enhanced Ultrasonography (CEUS) performed with 2nd generation contrast agents and new dedicated software represent a useful tool that improved not only the diagnostic accuracy of ultrasonography, but allowed the detection of 
vascularization and tissue perfusion in real-time and with excellent spatial resolution in many fields.

CEUS is a safety (Piscaglia 2006, Abdelmoneim 2009), emerging tool that allows to obtain more reliable information in daily practice (Claudon, 2008). As a matter of fact, regarding the evaluation of carotid atherosclerosis, CEUS provides an enhanced assessment of the arterial lumen and plaque morphology, an improved resolution of carotid intima-media thickness, and they even allow the direct visualization of adventitial vasa vasorum and plaque neovascularization (Purushothman, 2006; Feinstein, 2004). Feinstein et al reported in 2006 first experiences identifying carotid plaque neovascularization with CEUS in a patient with a significant and symptomatic carotid stenosis, confirmed by the histological findings after endarterectomy. They also observed the neovascularization regression after 8 months of statins therapy in a plaque of a diabetic patient. In a recent paper from our group (Vicenzini, 2007), we also observed that plaque vascularization can be easily detected with contrast ultrasound imaging in the the fibrous and fibro-fatty tissue and not observed in the calcific nor in the necrotic and haemorrhagic areas, as expression of plaque remodeling. More evidences are now confirming the reliability of this technique (Shah, 2007; Huang, 2008, Staub, 2010; Coll 2010).

In our research, we focus on the possibility to detect neoangiogenesis in carotid plaques with ultrasound and second-generation ultrasound contrast agents. In order to detect possible differences between atherosclerotic lesions correlated with clinical symptomatology, we studied patients to be submitted to carotid endarterectomy for severe, hemodynamic internal carotid artery stenosis, both asymptomatic as well as acute/recent symptomatic cerebrovascular patients. Data obtained were also confronted with postoperative histological findings. Moreover, asymptomatic patients with moderate internal carotid artery stenosis suitable for medical treatment and sonographic surveillance were investigated. Aim of our study was to evaluate the characteristics of carotid plaque vascularization detected with contrast ultrasound investigation according clinical findings, and to correlate contrast ultrasound investigation with histology and immunohistochemichal (VEGF, MMP3,CD 31-34).

\subsection{Methods of CEUS investigation}

Carotid duplex scanning was performed with an Acuson/Siemens Sequoia 512 and Siemens S2000 scanners, equipped with the software "Cadence Contrast Pulse Sequencing technology" (Cadence CPS). Linear phased array probes (6, 8 and $15 \mathrm{Mhz}$ for the Sequoia, 9, 14, $18 \mathrm{MHz}$ for the S2000). General Electric (GE Logiq9) and Philips IUD 22 scanner were also used. The same presets were maintained for all patients, in order to reduce pitfalls reproducibility.

Internal carotid artery plaques were digitally documented in B-Mode, Color and Power modes on both longitudinal and transversal scans, to obtain the best visualization of the atherosclerotic lesions. Angle corrected blood flow velocities were obtained with Pulsed Wave Doppler at the maximum site of stenosis. Plaque echographic morphology has been described according to criteria already well-established in literature (Gray-Weale, 1988; El Bargouthy, 1995): plaque structure according to the echogenicity, and considered as hyperechoic with acoustic shadow, hyperechoic, isoechoic, hypoechoic, and consequently as calcific, fibrous, fibro-calcific, fibro-fatty/haemorrhagic. Plaque surface as regular, irregular and ulcerated, when a surface irregularity $>2 \mathrm{~mm}$ was detected. Echogenicity was also quantified with Gray Scale Median (GSM) computerized analysis (Biasi, 1999) in order to 
better define the plaque risk. The degree of stenosis was evaluated according to European Carotid Surgery Trial criteria (ECST, 1995), as percentage of the difference between the original and the residual lumen at the maximum site of stenosis and to the relative increase of blood flow velocities (Sabeti, 2004).

Contrast ultrasound investigation was performed, as already described (Vicenzini, 2007), after small repeated bolus injections of SonoVue (Bracco Altana Pharma, Konstanz, Germany) in an antecubital vein (20 Gauge Venflon), followed by saline flushes. After identifying the plaque on longitudinal and transverse scans, and after having obtained the baseline B-mode, Color and Power images of the plaque, the $15 \mathrm{Mhz}$ linear array probe with a mechanical index varying from 0.4 to 1.4 with CPS continuous real-time recording software was used to achieve the best visualization of plaque morphology and vascularization, in the same longitudinal view. Freezed images and clips were stored throughout the investigation, in order to compare the basal images with the same images obtained after contrast administration. The "Contrast Agent only" software feature, in which the image is derived only from the signals originating from the microbubbles, has been used. All the investigations were digitally stored onto an external hard-disk for the offline review analysis, performed by two different sonographers.

Carotid endarterectomies have been carefully performed in order to obtain the whole plaque with minimal trauma. The removed plaques were immediately placed in formalin and subsequently probed with hematossilin-eosin coloration, to have a general view of plaque cellularity, and immunostained with antibodies for Vascular Endotelial Growth Factors (VEGF) and Matrix MetalloProteinases 3 (MMP3) (DAKO, Glostrup Denmark). After the complete observation of the lesion, the regions of interest observed at ultrasound images were identified and discussed with the sonographers.

\section{Contrast ultrasound findings}

Ultrasound contrast agent microbubbles are visualized few seconds after the injection as a hyperechoic dynamic flow in the carotid vessel lumen, providing an enhanced visualization of the carotid intima-media complex and a better identification of the plaque surface. They may be of help in better defining plaque surface and to indentify plaque ulceration, especially when B-Mode imaging and Color imaging are blurry or have a low definition.

Mainly during the diastolic cardiac phase, probably due to the reduced local pressure, the distribution of UCA inside the plaque allowed the visualization of vascularization. Microvesseles were detected through the visualization of microbubbles penetrating in the iso-hyperechoic fibrous and fibro-fatty tissue, as a little vessel perpendicular to the carotid lumen, regardless the severity of stenosis.

Further, a different pattern of plaque vascularization was observed in the acute symptomatic patients, represented by a major and more diffuse contrast enhancement, completely different from the pattern of the majority of the asymptomatic plaques. These data have been confirmed by other Authors (Xiong, 2009; Staub, 2010, Chowdhury ,2010, Cosgrove, 2009).

Histological specimens with immunostaining obtained from CEA confirmed a relevant angiogenesis in symptomatic plaques when compared to asymptomatic ones. From our experience (Vicenzini, 2007, 2009; Giannoni, 2009 a, 2009 b), we observed that microbubbles diffuse easily in the fibrous tissue of carotid plaques and that histologically correspond to the newly generated vessels, so confirming that plaques angiogenesis could be related to 


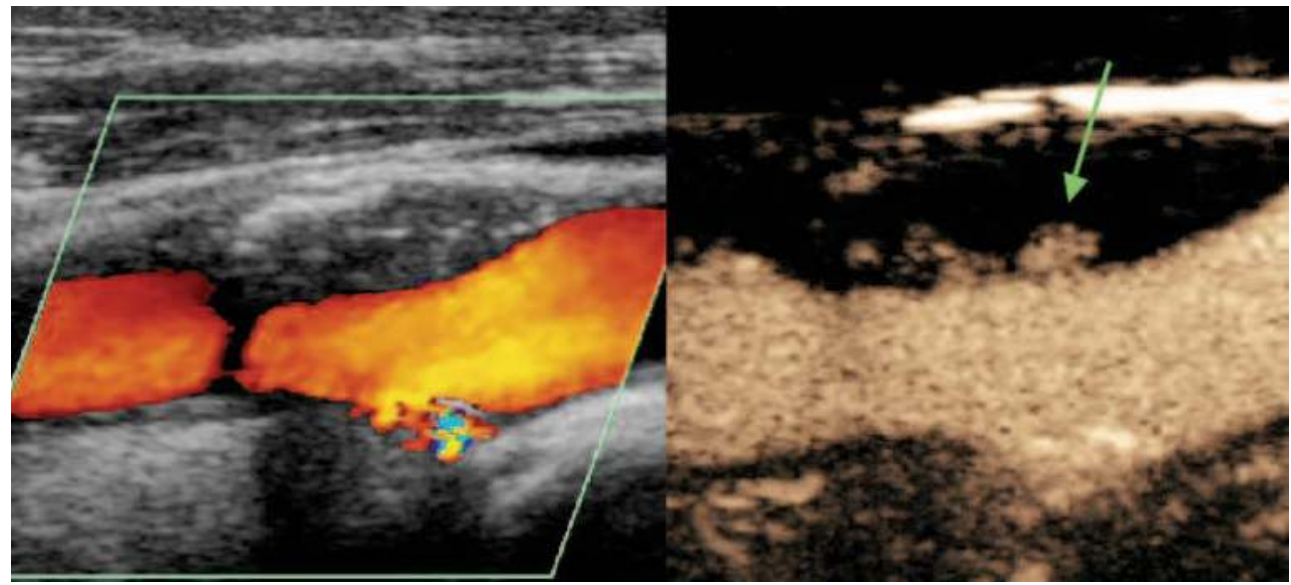

Fig. 1. Contrast carotid ultrasound of a ulcerated plaque. Ultrasound contrast agents better identify plaque surface and ulceration (green arrow).

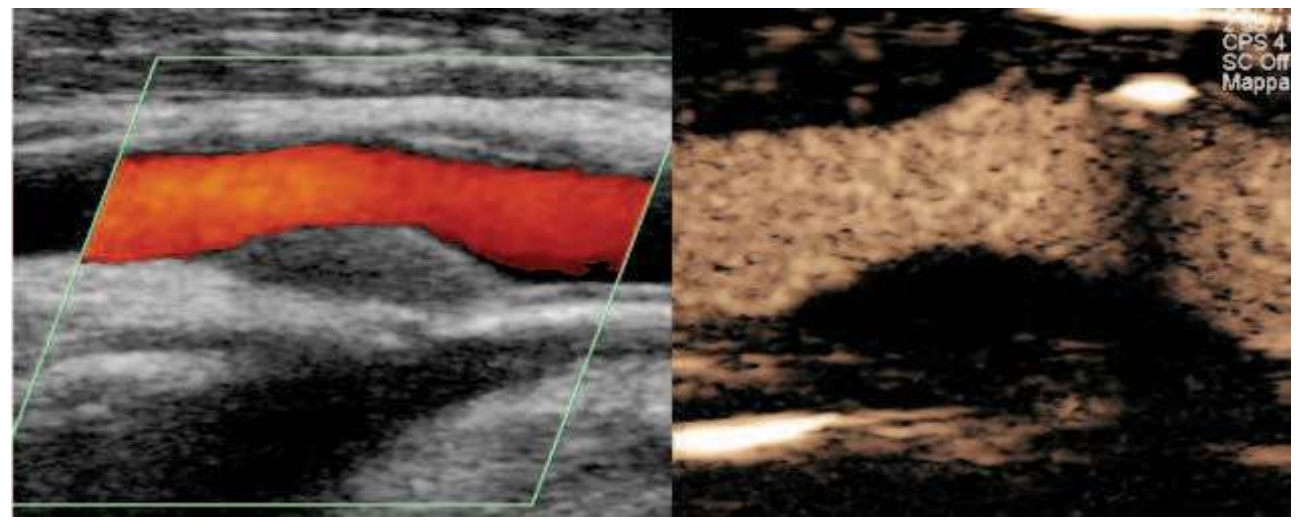

Fig. Isoechoic, fibrous plaque with regular surface determining moderate internal carotid artery stenosis in an asymptomatic patient. No vascularization observed at contrast ultrasound.

progression and remodeling. In these regards, several Authors reported the strong histological correlation between the density of the new vessels in the intima and the incidence of luminal stenosis, the extent of chronic inflammatory infiltrates, the evidence of granulation tissue, thus confirming that symptomatic coronary and carotid artery plaques are characterized by a high vascularized pattern (McCarthy, 1999; Mofidi, 2001; Fleiner, 2004; Spagnoli, 2004; Dunmore, 2007).

The relevance of angiogenesis in atherosclerosis is driving efforts to develop accurate and reliable imaging modalities able to quantify plaque neovessels in-vivo. The ideal noninvasive technique should have a high resolution and be widely available and reproducible. In cardiology, angiogenesis and microvessels observed in coronary atheromas in histological studies have proven to be strongly associated with unstable angina and myocardial infarction. These observations lead then to the concept that the coronary atherosclerotic 
plaque, when in a late phase of development, becomes richly vascularized, unstable and responsible of the coronary artery occlusion and/or distal embolization, with consequent myocardial ischemic damage (Fryer, 1987; El Barghouty, 1995; Mofidi, 2001; Spagnoli, 2004). Morevoer, in our experience, contrast ultrasound shows vasa-vasorum and plaque newlyformed microvessels with an outward-inward direction, probably witnessing the patophysiological mechanism responsible of intraplaque microvessels rupture resulting in plaque increase of volume and surface rupture, trombotically active. The immunohistochemical sampling confirmed the relevant neoangiogenesis in these areas. On the other hand, the vascularization pattern was quite different in asymptomatic plaques, that showed less contrast enhancement with histological demonstration of more mature microvessels of higher caliber, rarely distributed in the plaque context. These contrast ultrasonographic findings are confirming histological data showing that every plaque has its own vascularization and that neoangiogensis is relevant in the unstable and symptomatic carotid plaque, as in the coronary arteries (Barger, 1984). New vessels formed within an atherosclerotic lesion have to be considered a "locus minoris resistentiae", because they are particularly prone to rupture, thus causing intra-plaque haemorrhage, increased plaque volume and instability. Several factors have been identified as contributors to the neovascular response of the atherosclerotic plaque: hypoxia and ischemia occurs when the intima and media undergoes thickening, inducing the production of angiogenic factors such as vascular endothelial grow-factor (VEGF), in particular in the diabetic patient (Williamson 1993). With the rupture of these microvessels, intraplaque haemorrhage stimulates the inflammatory response of macrophages and $\mathrm{T}$ cells to produce angiogenic factors, further promoting angiogenesis and increase of plaque volume.

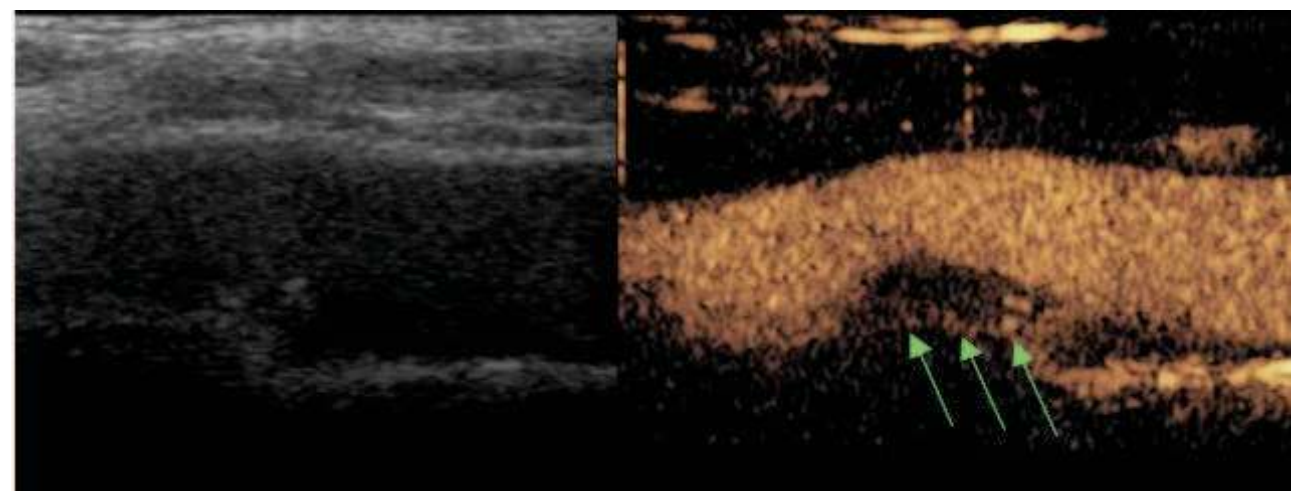

Fig. Acute symptomatic vascularized plaque. Green arrows show microbubbles in the plaque texture.

\section{Role of inflammation and intraplaque angiogenesis}

The patophysiological mechanisms responsible for progression and change towards carotid plaque instability remain incompletely defined. Consequently, there is an important need to identify if other elements play a key role in the progression and embolism from carotid plaques. Nowadays, the importance of inflammation and inflammatory markers has been claimed as a fundamental factor involved in the development and progression of the 
atherosclerotic plaques; furthermore, the association between inflammation, atherosclerosis progression and cardiovascular events have been well established for coronary and carotid artery diseases (Libby, 2002; Ridker, 2003, Monaco 2009, Monaco 2010, Shalhoub 2009, Shalhoub 2010.). Histological studies have observed that stable plaques are indeed characterized by a chronic inflammatory infiltrate, whereas vulnerable and ruptured plaques are characterized by an active inflammation and "plaque activity" processes involved in the thinning of the fibrous cap, predisposing to plaque rupture (de Nooijer, 1996; Spagnoli, 2004; Spagnoli, 2007). Nonetheless, the occurrence of high plaque neovascularization originating from the external layers and the increased number of adventitial vasa-vasorum have been considered, and confirmed in histological studies, as other important predictors of unstable achromatic lesions in symptomatic and asymptomatic carotid artery plaques (Mofidi, 2001; Dunmore, 2007), through different mechanisms that may be connected with plaque inflammation. Angiogenesis occurs indeed regularly within atherosclerotic plaques and plaque vulnerability and symptomatic carotid disease have been associated with an increased number of microvessels (Fleiner, 2004). It is indeed believed that the absence of pericytes in new vessels causes the "leak" of potentially noxious and inflammatory plasma components into the extracellular matrix of the media/intima, increasing the plaque volume, gradually reducing vessel wall oxygen diffusion, enhancing further angiogenesis. In the final phase, the plaque is enveloped in adventitial vasa vasorum and rich network of small caliber microvessels, a hallmark of symptomatic atherosclerosis (Carlier, 2005). The processes that lead to intramural haemorrhage and plaque ulcerations are other important issues that have been extensively studied. Some theories claims the hypothesis that atherosclerosis progression is due to an "outside-in" process and, effectively, intimal vessels originating from the adventitial layers have been observed much more frequently that those originating from the luminal side, resembling microvessels that grow within tumors (Kumamoto, 1995; Mofidi, 2001; Dunmore, 2007). This datum was also confirmed in our patients, in which the microbubbles diffusion seems to be oriented from the external adventitial layers towards the internal intimal lumen and, constantly, through a little vessel present under the plaque ulcerations.

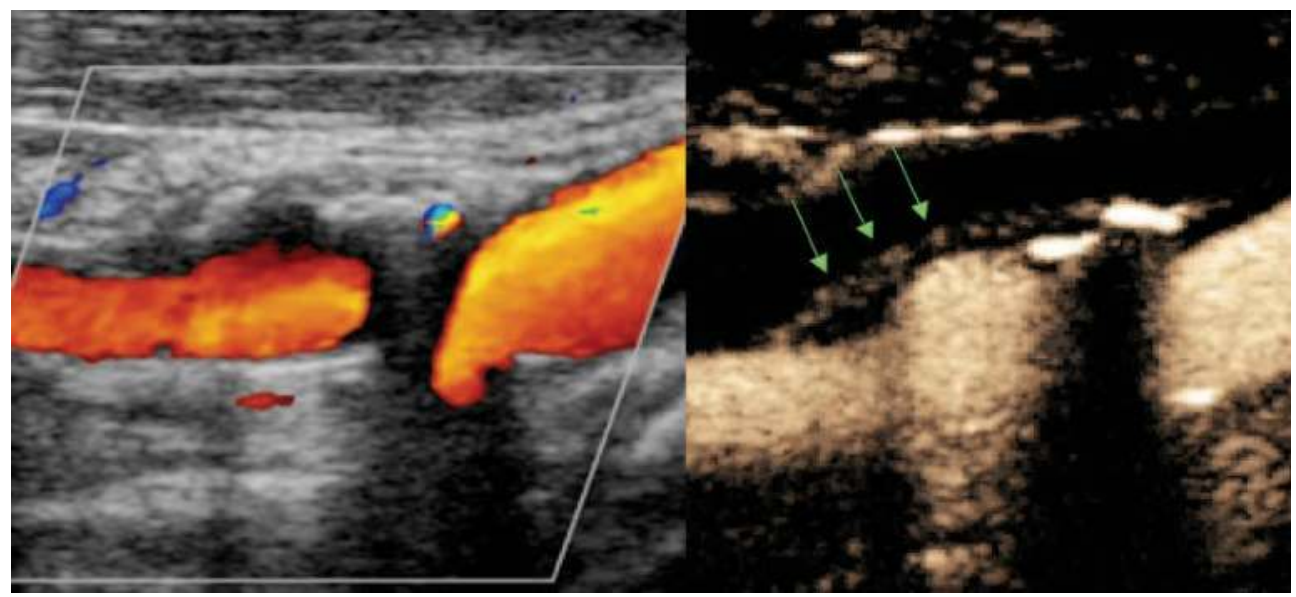

Fig. Plaque vascularization in the area below ulcerations 
This latter observation further supports the theory that intraplaque hemorrhage and ulcerations can be related to the rupture of newly formed intraplaque microvessels, that, being immature and with a thin wall, are submitted to local triggering factors such as mechanical forces and shear stress. The histological observation that intraplaque hemorrhages are common in every atherosclerotic lesion, usually deep and not connected with the vessel lumen, is another indicator that the bleeding originates locally (Bornstein, 1990; Milei, 1998).

\section{What is new and good, what is not good}

The most relevant information that can be obtained with CEUS is that plaque angiogenesis is possible to be demonstrated in vivo and in "real time". A limitation of this approach is the modality of the evaluation of these patterns of vascularization: at present, a method of a real numerical objective quantification is indeed not available for carotid plaques. Differently from the evaluation of myocardium, in which tissue perfusion is the expression of a normal condition, and differently from small coronary plaques, in which there is a different ratio due to the size of the vessel, this pattern may interest limited regions of the carotid plaque and the quantitative analysis of the mean signal enhancement deriving from the whole plaque cannot be easily applicable. The semi-quantitative evaluation, being arbitrary, may not be considered as really representative of plaque vascularization, also because evaluated in bi-dimensional images on user-defined region of interest. The identification of these patterns requires then a very careful visual and morphological observation. Moreover, at present, conventional CEUS imaging is provided through a bidimensional plane, that is not able to give complete information regarding the whole plaque angiogenesis, also considering that plaques can be either or not vascularized with avascular areas, due to necrosis, hemorrhage or calcifications.

\section{Future research}

Standard ultrasound carotid duplex is one of the most diffuse and available technique to assess plaque morphology and to identify the "plaque at risk". With Ultrasound Contrast Agents, more information on carotid atherosclerosis can be identified in routine clinical practice: as a matter of fact, an enhanced assessment of the arterial lumen and plaque morphology and an improved resolution of carotid intima-media thickness can be obtained. Consistent data also report that the direct visualization of adventitial vasa vasorum and plaque neovascularization is now possible with this technique, with the main advantage of being simple, low cost, minimally invasive and "in vivo". These data could open future perspectives to study unstable carotid plaques with contrast ultrasound to evaluate plaque progression and the possible efficacy of medical therapies. In these regards, the efficacy of statins in cardiovascular prevention has been established (Mizuguchi, 2008). Several papers suggested that the pleiotrophic effects of statins may contribute to plaque stabilization reducing inflammation (Yamagami 2008; Kadoglou, 2008) and, potentially, all these features could be evaluated with contrast ultrasound. The innovative aspect of this study is that data obtained from histological specimens are detectable "in vivo", with minimal invasiveness, by contrast ultrasound investigation. 


\section{References}

A randomised, blinded, trial of clopidogrel versus aspirin in patients at risk of ischaemic events (CAPRIE). CAPRIE Steering Committee. Lancet (1996); 348: 1329-1339

Abbott AL, Bladin CF, Levi CR, Chambers BR What should we do with asymptomatic carotid stenosis? Int J Stroke (2007); 2: 27-39

Abdelmoneim SS, Bernier M, Scott CG, Dhoble A, Ness SA, Hagen ME, Moir S, McCully RB, Pellikka PA, Mulvagh SL. Safety of contrast agent use during stress echocardiography: a 4-year experience from a single-center cohort study of 26,774 patients. JACC Cardiovasc Imaging. (2009); 2: 1048-1056.

Asymptomatic Carotid Atherosclerosis Study Group. Carotid endarterectomy for patients with asymptomatic internal carotid artery stenosis. JAMA (1995); 273: 1421-1428

Barger AC, Beeuwkes R, Lainey LL, Silverman KJ. Hypothesis: vasa vasorum and neovascularization of human coronary arteries. A possible role in the pathophysiology of atherosclerosis. NEJM (1984); 310: 175-177

Barnett HJ, Taylor DW, Eliasziw M, Fox AJ, Ferguson GG, Haynes RB, Rankin RN, Clagett GP, Hachinski VC, Sackett DL, Thorpe KE, Meldrum HE, Spence JD Benefit of carotid endarterectomy in patients with symptomatic moderate or severe stenosis. North American Symptomatic Carotid Endarterectomy Trial Collaborators. N Engl J Med (1998); 339: 1415-1425.

Biasi GM, Sampaolo A, Mingazzini P, De Amicis P, El-Barghouty N, Nicolaides AN: Computer analysis of ultrasonic plaque echolucency in identifying high risk carotid bifurcation lesions. Eur J Vasc Endovasc Surg (1999); 17: 476-479

Bornstein NM, Krajewski A, Lewis AJ, Norris JW. Clinical significance of carotid plaque hemorrhage. Arch Neurol (1990); 47: 958-959

Carlier S, Kakadiaris IA, Dib N, Vavuranakis M, O'Malley SM, Gul K, et al. Vasa vasorum imaging: a new window to the clinical detection of vulnerable atherosclerotic plaques. Curr Atheroscler Rep (2005); 7: 164-169

Carr S, Farb A, Pearce WH, Virmani R, Yao JS. Atherosclerotic plaque rupture in symptomatic carotid artery stenosis. J Vasc Surg (1996); 23: 755-765

Chowdhury M, Ghosh J, Slevin M, et al A comparative study of carotid atherosclerotic plaque microvessel density and angiogenic growth factor expression in symptomatic versus asymptomatic patients Eur J Vasc Endovasc Surg. 2010 ; 39:388-395.

Claudon M, Cosgrove D, Albrecht T, Bolondi L, Bosio M, Calliada F, Correas JM, Darge K, Dietrich C, D'Onofrio M, Evans DH, Filice C, Greiner L, Jäger K, Jong N, Leen E, Lencioni R, Lindsell D, Martegani A, Meairs S, Nolsøe C, Piscaglia F, Ricci P, Seidel G, Skjoldbye B, Solbiati L, Thorelius L, Tranquart F, Weskott HP, Whittingham T. Guidelines and good clinical practice recommendations for contrast enhanced ultrasound (CEUS) - update 2008. Ultraschall Med. (2008); 29: 28-44.

Cole JE, Mitra AT, Monaco C. Treating atherosclerosis: the potential of Toll-like receptors as therapeutic targets. Expert Rev Cardiovasc Ther. (2010); 8: 1619-1635.

Cole JE, Georgiou E, Monaco C.The expression and functions of toll-like receptors in atherosclerosis. Mediators Inflamm. (2010)3 93946. Epub 2010 Jun 24. Review 
Coll B, Nambi V, Feinstein SB. New advances in noninvasive imaging of the carotid artery: CIMT, contrast-enhanced ultrasound, and vasa vasorum. Curr Cardiol Rep. (2010); 12: 497-502.

De Bray JM, Baud JM, Dauzat M. Consensus concerning the morphology and the risk of carotid plaques. Cerebrovasc Dis (1996);7:289-296

de Nooijer R, Verkleij CJ, von der Thüsen JH, Jukema JW, van der Wall EE, van Berkel TJ, et al. Lesional over expression of matrix metalloproteinase-9 promotes intraplaque hemorrhage in advanced lesions but not at earlier stages of atherogenesis. Arterioscler Thromb Vasc Biol (2006); 26: 340-346

Diener HC, Bogousslavsky J, Brass LM, Cimminiello C, Csiba L, Kaste M, Leys D, MatiasGuiu J, Rupprecht HJ; MATCH investigators. Aspirin and clopidogrel compared with clopidogrel alone after recent ischaemic stroke or transient ischaemic attack in high-risk patients (MATCH): randomised, double-blind, placebo-controlled trial. Lancet. (2004) ;364: 331-337

Dixon S, Pais SO, Raviola C.: Natural history of non stenotic ulcerative lesions of the carotid artery. Arch Surg (1982); 117: 1493-1498

Dunmore BJ, McCarthy MJ, Naylor AR, Brindle NP. Carotid plaque instability and ischemic symptoms are linked to immaturity of microvessels within plaques. J Vasc Surg (2007); 45: 155-159

El-Barghouty N, Gerulakos G, NicolaidesAN, Androulakos A, Bahn V: Computer assisted carotid plaque characterization. Eur JVasc Endov Surg (1995); 9: 389-393

Engel-Nitz NM, Sander SD, Harley C, Rey GG, Shah H. Costs and outcomes of noncardioembolic ischemic stroke in a managed care population. Vascular Health and Risk Management .6 : 905 - 913, 2010)European Carotid Surgery Trialists' Collaborative Group. Randomised trial of endarterectomy for recently symptomatic carotid stenosis: final results in the MRC European carotid surgery trial (ECST). Lancet (1998); 351: 1379-1387

European Carotid Surgery Trialists' Collaborative Group. MRC European Carotid Surgery Trial: interim results for symptomatic patients with severe (70-99\%) or with mild (0-29\%) carotid stenosis. Lancet. (1991); 337: 1235-1243

Executive Committee for the Asymptomatic Carotid Atherosclerosis Study. Endarterectomy for asymptomatic carotid artery stenosis. JAMA. (1995); 273:1421-1428

Feinstein SB. Contrast ultrasound imaging of the carotid artery vasa vasorum and atherosclerotic plaque neovascularization. J Am Coll Cardiol (2006); 48: 236-243

Feinstein SB. The powerful microbubble: from bench to bedside, from intravascular indicator to therapeutic delivery system, and beyond. Am J Physiol Heart Circ Physiol (2004); 287: H450-457.

Fisher M, Paganini-Hill A, Martin A, et al. Carotid plaque pathology: thrombosis,ulceration, and stroke pathogenesis. Stroke (2005); 36:253-257

Fleiner M, Kummer M, Mirlacher M, Sauter G, Cathomas G, Krapf R, Biedermann BC. Arterial neovascularization and inflammation in vulnerable patients: early and late signs of symptomatic atherosclerosis. Circulation. (2004); 110: 2843-2850

Fryer J.A, Myers PC, Appleberg M Carotid intraplaque hemorrhage: the significance of neovascularity. J Vasc Surg (1987); 6: 341-349 
Geiringer E: Intimal vascularisation and atherosclerosis. Histologic characteristics of carotid atherosclerotid plaque. J Pathol Bacteriol (1951); 63: 201-211

Geroulakos G, Ramaswami G, Nicolaides A. Characterisation of symptomatic and asymptomatic carotid plaques using high resolution real time ultrasound. Br J Surg (1993); 80:1274-1277

Giannoni MF, Vicenzini E, Citone M, Ricciardi MC, Irace L, Laurito A, Scucchi LF, Di Piero V, Gossetti B, Mauriello A, Spagnoli LG, Lenzi GL, Valentini FB. Contrast carotid ultrasound for the detection of unstable plaques with neoangiogenesis: a pilot study. Eur J Vasc Endovasc Surg. (2009); 37: 722-727

Giannoni MF, Vicenzini E. Focus on the "unstable" carotid plaque: detection of intraplaque angiogenesis with contrast ultrasound. Present state and future perspectives. Curr Vasc Pharmacol. (2009); 7: 180-184 a

Goldstein LB, Bushnell CD, Adams RJ, Appel LJ, Braun LT, Chaturvedi S, Creager MA, Culebras A, Eckel RH, Hart RG, Hinchey JA, Howard VJ, Jauch EC, Levine SR, Meschia JF, Moore WS, Nixon JV, Pearson TA; on behalf of the American Heart Association Stroke Council, Council on Cardiovascular Nursing, Council on Epidemiology and Prevention, Council for High Blood Pressure Research, Council on Peripheral Vascular Disease, and Interdisciplinary Council on Quali. Guidelines for the Primary Prevention of Stroke. A Guideline for Healthcare Professionals From the American Heart Association/American Stroke Association. Stroke. 2010 Dec 6.

Gray-Weale AC, Graham JC, Burnett JR, Byrne K, Lusby RJ.Carotid artery atheroma: Comparison of B-mode ultrasound appearance with preoperative pathology carotid endarterectomy sample J Cardiovasc Surg (1988); 29: 676-681

Griffin MB, Kyriacou E, Pattichis C, Bond D, Kakkos SK, Sabetai M, Geroulakos G, Georgiou N, Doré CJ, Nicolaides A. Juxtaluminal hypoechoic area in ultrasonic images of carotid plaques and hemispheric symptoms. J Vasc Surg. (2010) ; 52: 6976

Grønholdt ML, Nordestgaard BG, Schroeder TV, Vorstrup S, Sillesen H. Ultrasonic echolucent carotid plaques predict future strokes. Circulation (2001); 104:68-73

Halliday A, Mansfield A, Marro J, MRC Asymptomatic Carotid Surgery Trial (ACST) Collaborative Group. Prevention of disabling and fatal strokes by successful carotid endarterectomy in patients without recent neurological symptoms: randomised controlled trial. Lancet (2004); 363:1491-1502

Halliday A, Harrison M, Hayter E, Kong X, Mansfield A, Marro J, Pan H, Peto R, Potter J, Rahimi K, Rau A, Robertson S, Streifler J, Thomas D; Asymptomatic Carotid Surgery Trial (ACST) Collaborative GroupResults: 1 to 20 of 33 1.10-year stroke prevention after successful carotid endarterectomy for asymptomatic stenosis (ACST-1): a multicentre randomised trial. Lancet. (2010);37:1074-1084

Hennerici MG. The unstable plaque. Cerebrovasc Dis. 2004; 17 Suppl 3: 17-22.

Hobson RW 2nd, Mackey WC, Ascher E, Murad MH, Calligaro KD, Comerota AJ, Montori VM, Eskandari MK, Massop DW, Bush RL, Lal BK, Perler BA; Society for Vascular Surgery Management of atherosclerotic carotid artery disease: clinical practice guidelines of the Society for Vascular Surgery. J Vasc Surg. (2008 );48: 480-486 
Huang PT, Huang FG, Zou CP, Sun HY, Tian XQ, Yang Y, et al. Contrast-enhanced sonographic characteristics of neovascularization in carotid atherosclerotic plaques. J Clin Ultrasound. (2008); 36: 346-351

Huang P, Huang F, Cosgrove D. Analysis of Neovascularization within Carotid Plaques in Patients with Ischemic Stroke using Contrast-Enhanced Ultrasound . 12th World congress of Ultrasound in Medicine and Biology, Sydney sept 2009. Ultrasound in Medicine and Biology 2009; 35, (8S), S4.

Joakimsen O, Bonaa KH, Stensland-Bugge E. Reproducibility of ultrasound assessment of carotid plaque occurrence, thickness, and morphology. The Tromso Study. Stroke (1997);28: 2201-2207

Johnson JM, Kennely M, Decesale D, Morgan S, Sparrow S. Natural history of asymptomatic plaque. Arch Surg (1985); 120: 1010-1012

Kadoglou NP, Gerasimidis T, Moumtzouoglou A, Kapelouzou A, Sailer N, Fotiadis G, Vitta I, Katinios A, Kougias P, Bandios S, Voliotis K, Karayannacos PE, Liapis CD.Intensive lipid-lowering therapy ameliorates novel calcification markers and GSM score in patients with carotid stenosis.Eur J Vasc Endovasc Surg. (2008); 35: 661-668

Kakkos SK, Sabetai M, Tegos T, Stevens J, Thomas D, Griffin M, Geroulakos G, Nicolaides AN; Asymptomatic Carotid Stenosis and Risk of Stroke (ACSRS) Study Group. Silent embolic infarcts on computed tomography brain scans and risk of ipsilateral hemispheric events in patients with asymptomatic internal carotid artery stenosis. J Vasc Surg. (2009); 49:902-909

Kumamoto M, Nakashima Y, Sueishi K Intimal neovascularization in human coronary atherosclerosis: its origin and pathophysiological significance, Hum Pathol (1995); 26: $450-456$

Liapis CD, Bell PR, Mikhailidis D, Sivenius J, Nicolaides A, Fernandes e Fernandes J, Biasi G, Norgren L; ESVS Guidelines Collaborators . ESVS guidelines. Invasive treatment for carotid stenosis: indications, techniques. Eur J Vasc Endovasc Surg. (2009) 37: 119

Libby P, Ridker P, Maseri A. Inflammation and atherosclerosis. Circulation (2002); 105: 11351143

Lindner JR, Coggins MP, Kaul S, Klibanov AL, Brandenburger GH, Ley K. Microbubble persistence in the microcirculation during ischemia/reperfusion and inflammation is caused by integrin- and complement-mediated adherence to activated leukocytes. Circulation (2000); 101: 668-675

Markus H S, King A, Shipley M, Topakian R, Cullinane M, Reihill S, Bornstein N, , Schaafsma A. ACES A prospective observational study. Lancet Neurol (2010); 9: 663-671

Mathiesen EB, Bønaa KH, Joakimsen O. Echolucent plaques are associated with high risk of ischemic cerebrovascular events in carotid stenosis: the TROMSO study. Circulation. 2001; 103: 2171-2175

Mauriello A, Sangiorgi GM, Virmani R, Trimarchi S, Holmes DR Jr, Kolodgie FD, Piepgras DG, Piperno G, Liotti D, Narula J, Righini P, Ippoliti A, Spagnoli LG. A 
pathobiologic link between risk factors profile and morphological markers of carotid instability. Atherosclerosis. 2010; 208: 572-580

McCarthy MJ, Loftus IM, Thompson MM Angiogenesis and the atherosclerotic carotid plaque: an association between symptomatology and plaque morphology. J Vasc Surg (1999); 30: 261-268

Milei J, Parodi JC, Alonso GF, Barone A, Grana D, Matturri L. Carotid rupture and intraplaque hemorrhage: immunophenotype and role of cells involved. Am Heart J 1998; 136: 1096-1105

Mizuguchi Y, Oishi Y, Miyoshi H, Iuchi A, Nagase N, Oki T.Impact of statin therapy on left ventricular function and carotid arterial stiffness in patients with hypercholesterolemia.Circ J. (2008); 72: 538-544

Mofidi R, Crotty TB, McCarthy P, Sheehan SJ, Mehigan D, Keaveny TV Association between plaque instability, angiogenesis and symptomatic carotid occlusive disease, $\mathrm{Br} \mathrm{J}$ Surg (2001); 88: 945-950

Monaco C. Innate immunity meets arteriogenesis: The versatility of toll-like receptors. J Mol Cell Cardiol. 2010 Oct 21.

Monaco C, Gregan SM, Navin TJ, Foxwell BM, Davies AH, Feldmann M Toll-like receptor-2 mediates inflammation and matrix degradation in human atherosclerosis. Circulation. (2009); 120: 2462-2469

Nicolaides AN. Asymptomatic carotid stenosis and risk of stroke. Identification of a highrisk group. Int Angiol (1995); 14: 21-23

Paterson JC. Vascularization and hemorrhage of the intima of the atherosclerotic coronary arteries. Arch Pathol. (1936); 22: 313-324

Paterson JC: Capillary rupture with intimal haemorrhage as the causative factor in coronary thrombosis. Arch Pathol (1938); 25: 474-487

Piscaglia F, Bolondi L; Italian Society for Ultrasound in Medicine and Biology (SIUMB) Study Group on Ultrasound Contrast Agents. The safety of Sonovue in abdominal applications: retrospective analysis of 23188 investigations. Ultrasound Med Biol. (2006) ; 32: 1369-1375

Purushothaman KR, Sanz J, Zias E, Fuster V, Moreno PR. Atherosclerosis neovascularization and imaging. Curr Mol Med (2006); 6: 549-556

Randomised trial of endarterectomy for recently symptomatic carotid stenosis: final results of the MRC European Carotid Surgery Trial (ECST) Lancet. (1998); 351: 1379-1387

Reilly LM, Lusby RJ, Hugues L, Ferrell LD, Stoney RJ, Ehrenfeld WK. Carotid plaque histology using real-time ultrasonography: clinical and therapeutic implications. Am. J. Surg. (1983); 146: 188-193

Ridker PM, Buring JE, Cook NR, Rifai N. C-reactive protein, the metabolic syndrome, and risk of incident cardiovascular events: an 8-year follow-up of 14719 initially healthy American women. Circulation (2003); 107: 391-399

Rothwell PM, Eliasziw M., Carotid Endarterectomy Trialists Collaboration.et al. Endarterectomy for symptomatic carotid stenosis in relation to clinical subgroups and timing of surgery. Lancet (2004); 363: 915-24 
Sabeti S, Schillinger M, Mlekusch W, Willfort A, Haumer M, Nachtmann T, et al. Quantification of internal carotid artery stenosis with duplex US: comparative analysis of different flow velocity criteria. Radiology (2004); 232: 431-439

Shalhoub J, Owen D, Gauthier T, Monaco C, Leen E, Davies A H. The use of contrast enhanced ultrasound in carotid arterial disease. EJVES (2010); 39:381-387

Shalhoub J, Owen DR, Gauthier T, Monaco C, Leen EL, Davies AH. The use of contrast enhanced ultrasound in carotid arterial disease. Eur J Vasc Endovasc Surg. (2010); 39: 381-387

Shah F, Balan P, Weinberg M, Reddy V, Neems R, Feinstein M, et al. Contrast-enhanced ultrasound imaging of atherosclerotic carotid plaque neovascularization: a new surrogate marker of atherosclerosis? Vasc Med (2007); 12: 291-297

Setacci C, Lanza G, Ricci S, Cao PG, Castelli P, Cremonesi A, Inzitari D, Novali C, Pratesi C, Speziale F, Mangiafico S, Zaninelli A, Gensini GF; Stroke Prevention and Educational Awareness Diffusion (SPREAD). SPREAD Italian Guidelines for stroke. Indications for carotid endarterectomy and stenting J Cardiovasc Surg (Torino). 2009;50:171-182.

Spagnoli LG, Mauriello A, Sangiorgi G, et al. Extracranial thrombotically active carotid plaque as a risk factor for ischemic stroke. JAMA (2004); 292:1845-1852

Stary HC, Chandler AB, Dinsmore RE, Fuster V, Glagov S, Insull W Jr, Rosenfeld ME, Schwartz CJ, Wagner WD, Wissler RW. A definition of advanced types of atherosclerotic lesions and a histological classification of atherosclerosis. A report from the Committee on Vascular Lesions of the Council on Arteriosclerosis, American Heart Association. Circulation (1995); 92: 1355-1374

Staub D, Schinkel AF, Coll B, Coli S, van der Steen AF, Reed JD, Krueger C, Thomenius KE, Adam D, Sijbrands EJ, ten Cate FJ, Feinstein SB. Contrast-enhanced ultrasound imaging of the vasa vasorum: from early atherosclerosis to the identification of unstable plaques. JACC Cardiovasc Imaging. (2010); 3: 761-771

Staub D, Patel MB, Tibrewala A et al Vasa vasorum and plaque neovascularization on contrast-enhanced carotid ultrasound imaging correlates with cardiovascular disease and past cardiovascular events. Stroke. 2010

Vicenzini E, Giannoni MF, Benedetti-Valentini F, Lenzi GL. Imaging of carotid plaque angiogenesis. Cerebrovasc Dis. (2009); 27 Suppl 2: 48-54

Vicenzini E, Giannoni MF, Puccinelli F, Ricciardi MC, Altieri M, Di Piero V, Gossetti B, Valentini FB, Lenzi GL. Detection of carotid adventitial vasa vasorum and plaque vascularization with ultrasound cadence contrast pulse sequencing technique and echo-contrast agent. Stroke. (2007); 38: 2841-2843

Warburton L, Gillard J. Functional imaging of carotid atheromatous plaques. J Neuroimaging. (2006); 16: 293-301

Widder B, Paulat K, Hachspacher J. Morphological characterization of carotid artery stenoses by ultrasound duplex scanning.Ultrasound Med Biol (1990); 16: 349-354

Williamson JR, Chang K, Frangos M, Hasan KS, Ido Y, Kawamura T, et al. Hyperglycemic pseudohypoxia and diabetic complications. Diabetes (1993); 42: 801-813 
Xiong L, Deng YB, Zhu Y, Liu YN, Bi XJ. Correlation of carotid plaque neovascularization detected by using contrast-enhanced US with clinical symptoms. Radiology (2009); 251:583-589

Yamagami H, Sakaguchi M, Furukado S, Hoshi T, Abe Y, Hougaku H, Hori M, Kitagawa K. Statin Therapy Increases Carotid Plaque Echogenicity in Hypercholesterolemic Patients. Ultrasound Med Biol. (2008); 34: 1353-1359 


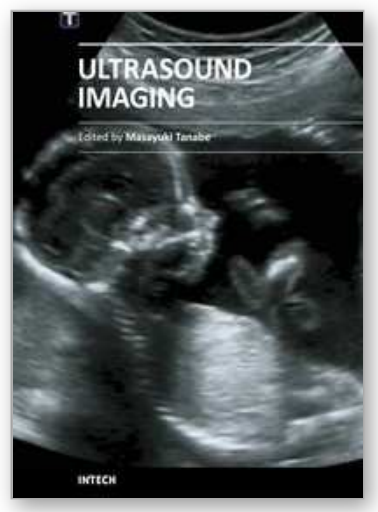

\author{
Ultrasound Imaging \\ Edited by Mr Masayuki Tanabe
}

ISBN 978-953-307-239-5

Hard cover, 210 pages

Publisher InTech

Published online 11, April, 2011

Published in print edition April, 2011

In this book, we present a dozen state of the art developments for ultrasound imaging, for example, hardware implementation, transducer, beamforming, signal processing, measurement of elasticity and diagnosis. The editors would like to thank all the chapter authors, who focused on the publication of this book.

\title{
How to reference
}

In order to correctly reference this scholarly work, feel free to copy and paste the following:

Maria Fabrizia Giannoni, Edoardo Vicenzini, Claudia Monaco and Piergiorgio Cao (2011). Contrast Enhanced Ultrasonography and Carotid Plaque Imaging: from the Hemodynamic Evaluation to the Detection of Neoangiogenesis - The New Approach to the Identification of the Unstable Plaque: from Morphology to Patophysiology, Ultrasound Imaging, Mr Masayuki Tanabe (Ed.), ISBN: 978-953-307-239-5, InTech, Available from: http://www.intechopen.com/books/ultrasound-imaging/contrast-enhanced-ultrasonography-and-carotidplaque-imaging-from-the-hemodynamic-evaluation-to-the-

\section{INTECH}

open science | open minds

\section{InTech Europe}

University Campus STeP Ri

Slavka Krautzeka 83/A

51000 Rijeka, Croatia

Phone: +385 (51) 770447

Fax: +385 (51) 686166

www.intechopen.com

\section{InTech China}

Unit 405, Office Block, Hotel Equatorial Shanghai

No.65, Yan An Road (West), Shanghai, 200040, China 中国上海市延安西路65号上海国际贵都大饭店办公楼 405 单元 Phone: $+86-21-62489820$

Fax: $+86-21-62489821$ 
(C) 2011 The Author(s). Licensee IntechOpen. This chapter is distributed under the terms of the Creative Commons Attribution-NonCommercialShareAlike-3.0 License, which permits use, distribution and reproduction for non-commercial purposes, provided the original is properly cited and derivative works building on this content are distributed under the same license. 